\title{
死結核菌の反覆注射にる万家鬼の賽驗的 澱粉樣變性に就て
}

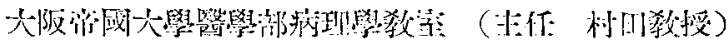

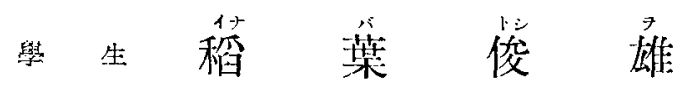

第 1 章 緒 言

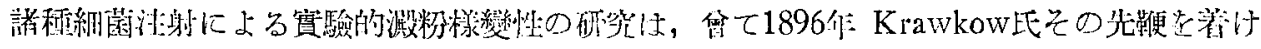

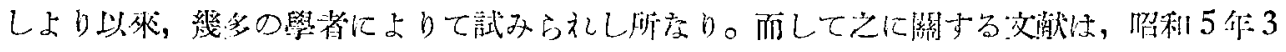

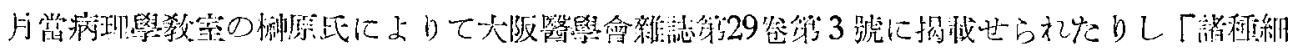

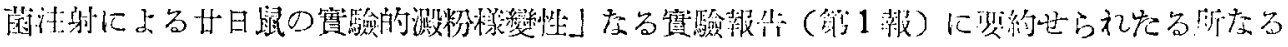

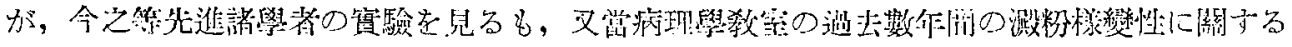

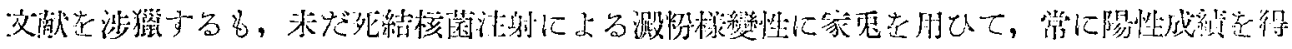

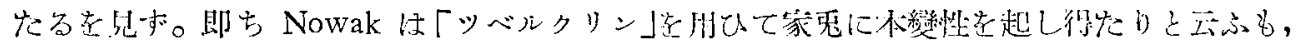

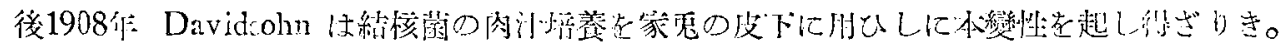

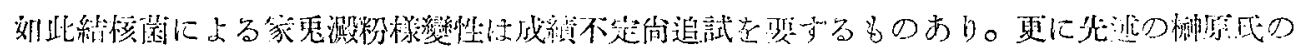

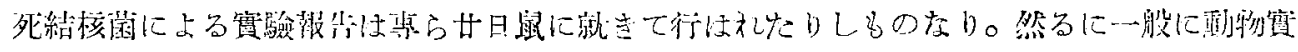

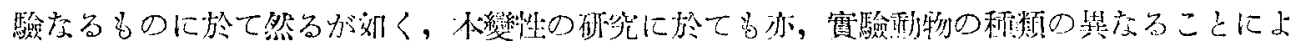

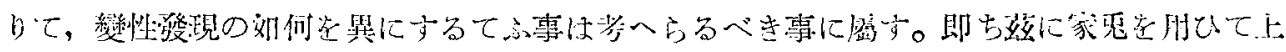

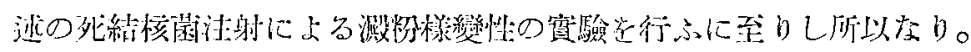

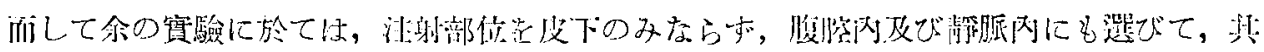

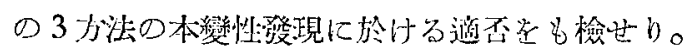

\section{第 2 章 宣 驗 方 法}

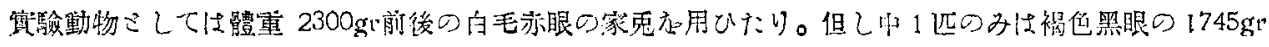
の家鬼衫り。

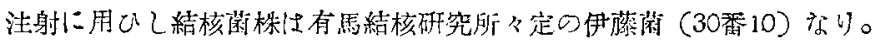

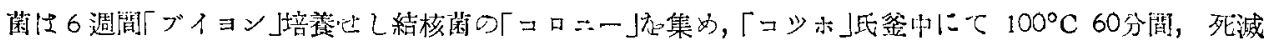

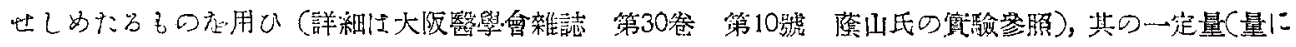

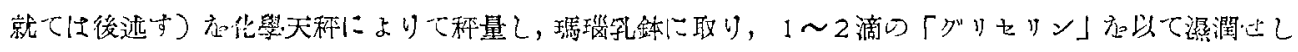

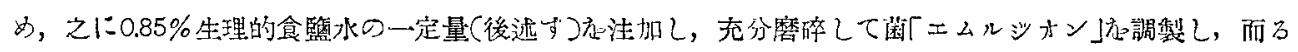




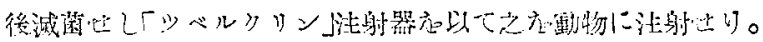

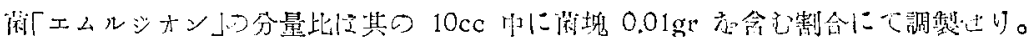

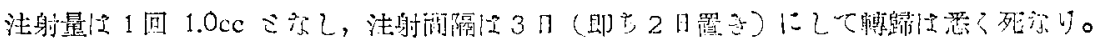

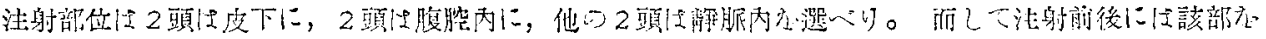
70\%「アルコール」にて消毒しり。

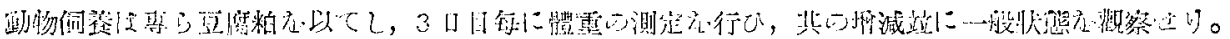

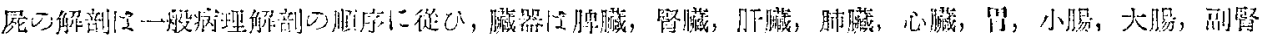

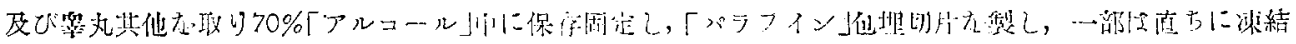

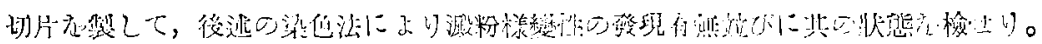

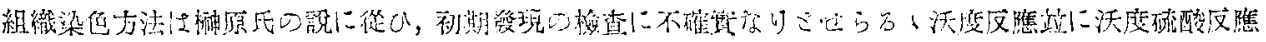

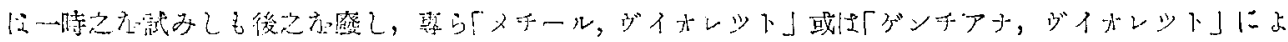

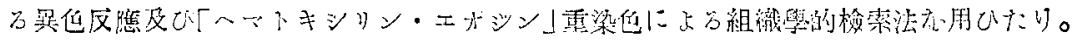

\section{第3 榇蕒 驗 成 績}

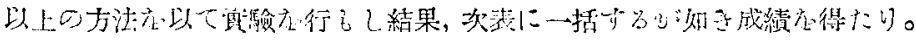

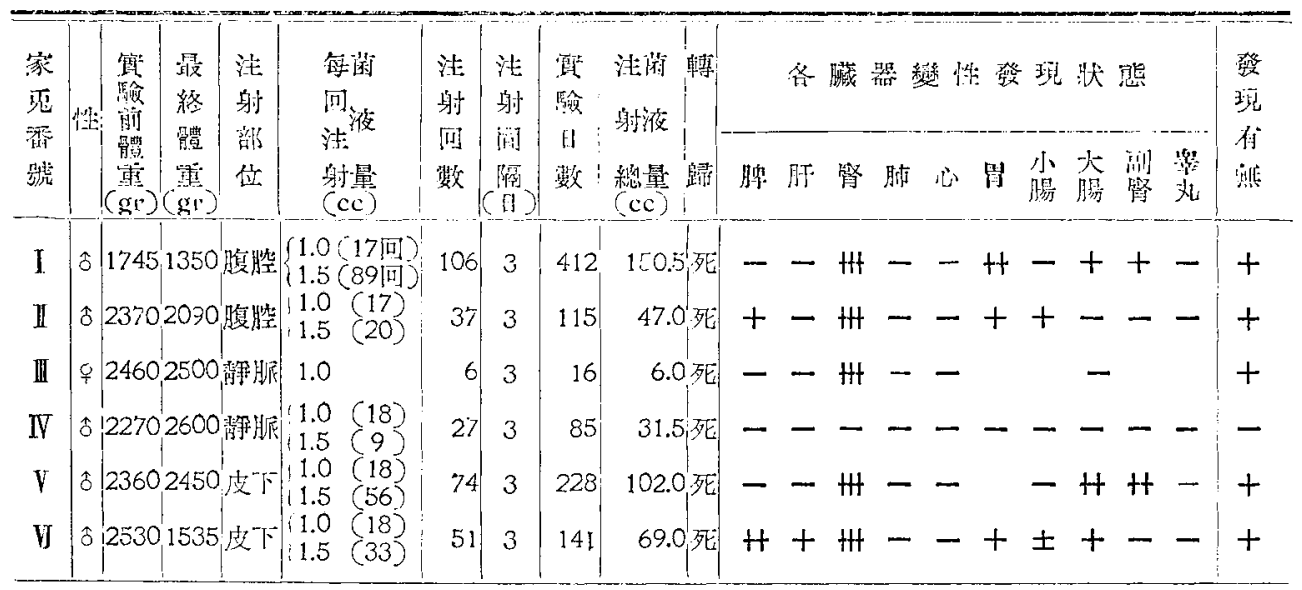

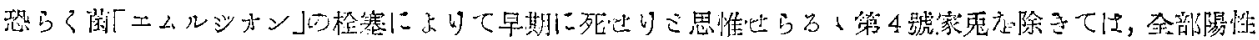

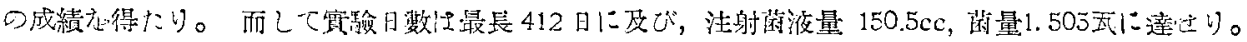

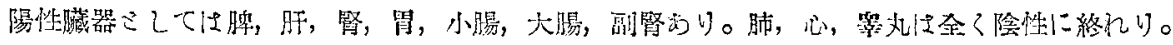

\section{第 4. 慞 實驗動物の臨床的泣に解剈的所見摘要}

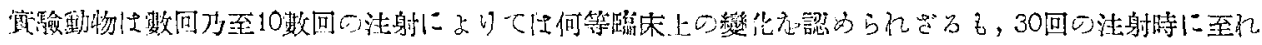

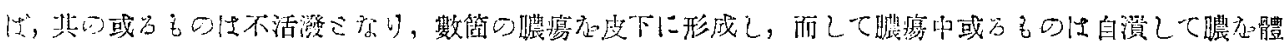


外に漏ベに至㟔。

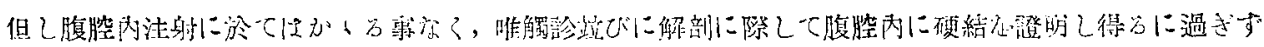

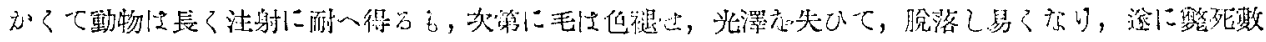

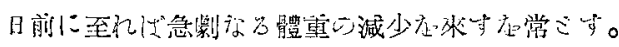

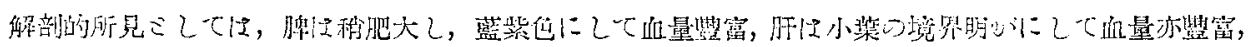

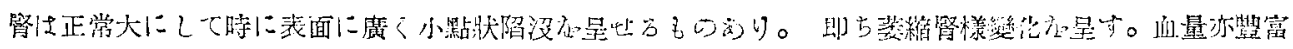

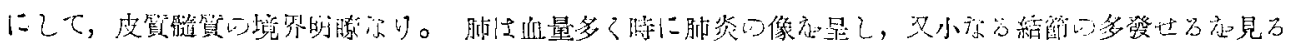

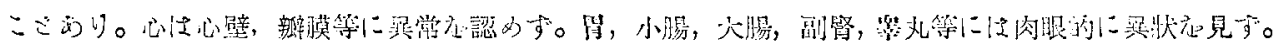

\section{第 5 章 各缄器の澱粉樣物質沈着状態}

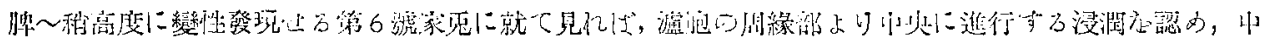

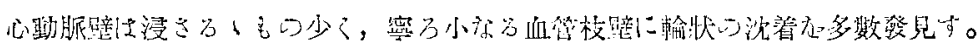

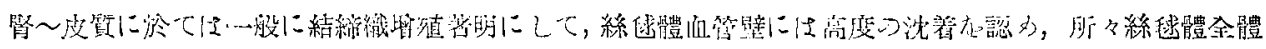

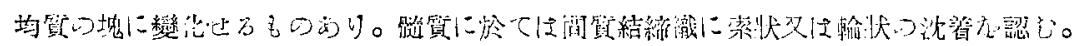

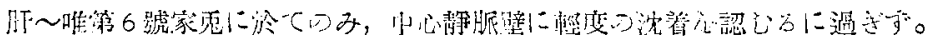

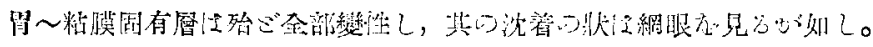

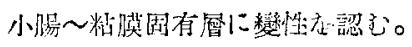

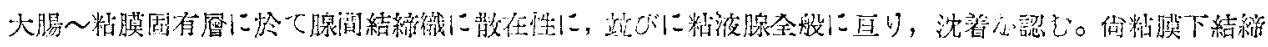

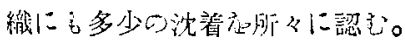

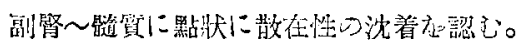

\section{第 6 章 考拔}

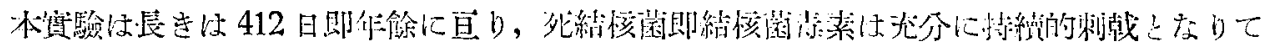

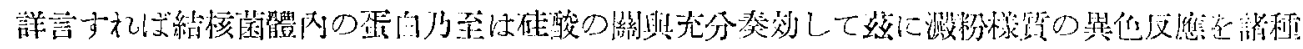

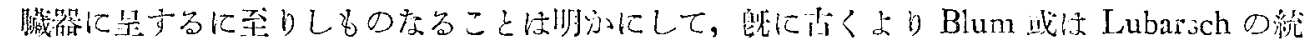

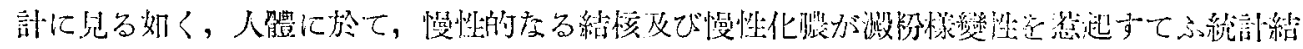
果と一致与尚字のな。

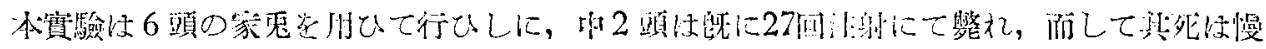

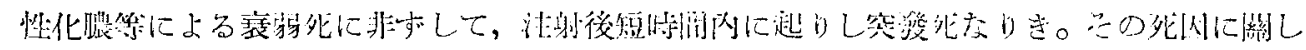

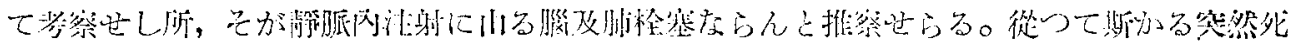

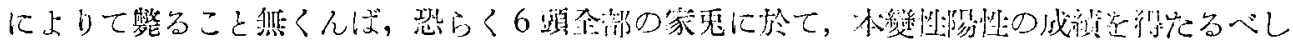

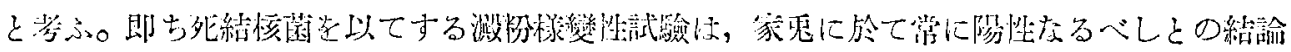

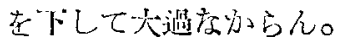




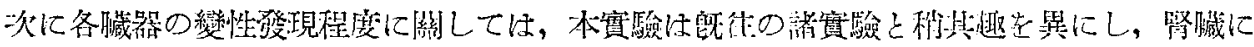

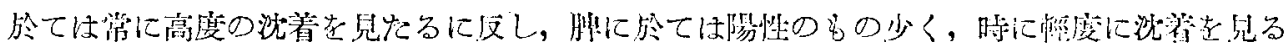

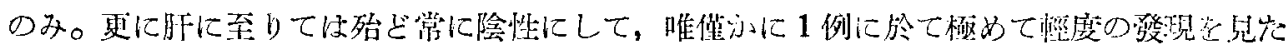

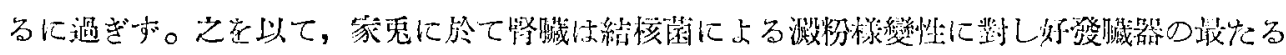
多の左ること在指摘过九と欲す。

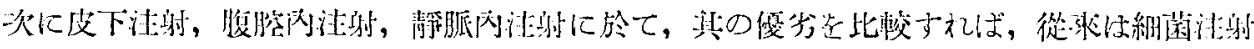

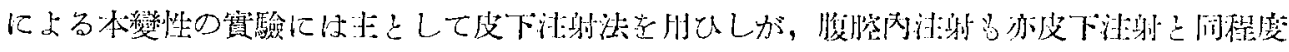

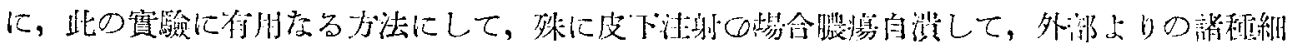

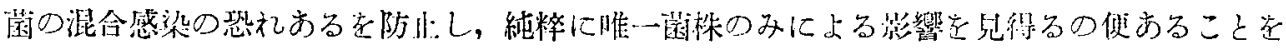

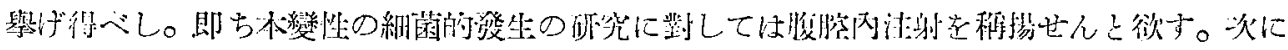

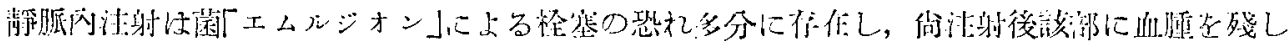

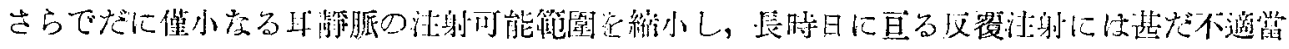
なりと哂觉。

\section{第 7 章 結 諭}

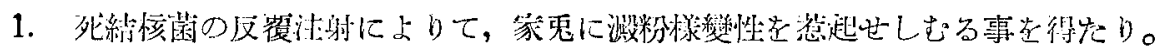

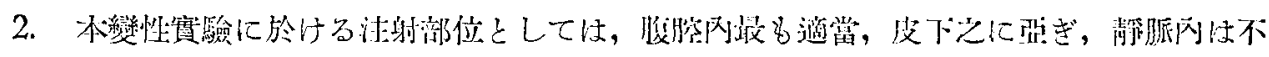
邀當なる在確め得をり。

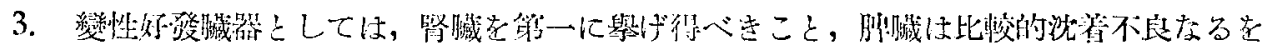
外礼占。

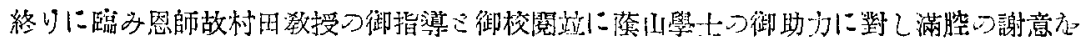
婊ず。

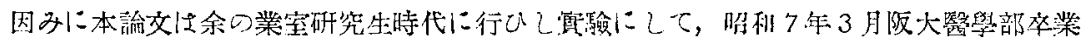

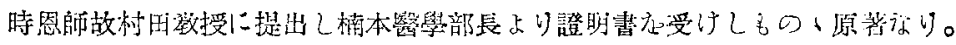

\section{主 要 荐 交 献}

1) C. Davidsohn : Arbeiten überAmyloid und Hyalin. Ergebn. d. allg. Path. u. path. Anot. Jg. 12. 1908.2 2) E. Leupold : Amyloid und Hyalin. Ergebn. d. allg. Path. u. pach. Anat.

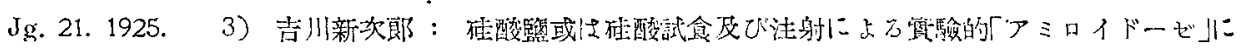

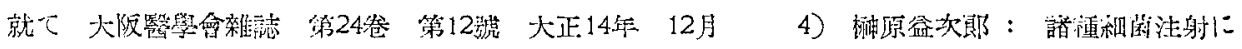

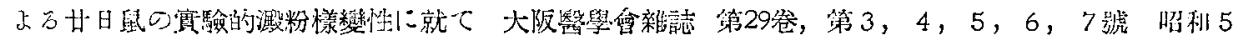
年 $3,4,5,6,7$ 月

(昭利15年11月2日受稿) 


\title{
ÜBER DIE EXPERIMENTELLE AMYLOIDOSE BEI KANINCHEN DURCH WIEDERHOLTE INJEKTIONEN VON DEN TOTEN TUBERKELBAZILLEN.
}

\author{
Vont \\ Student Tosio Inaba. \\ [Aus dem Pathologischen Institut dev Kaiserlichen Universität zu Osaka \\ (Direktor: Prof. M. Murata)]
}

Dieser Aufsatz ist ein Original, der zwischen 1930-1932 in meiner Studentenzeit im Pathologischen Institut der Kaiserlichen Universität zu Osaka geleistet war. Die Schlüsse sind folgendermassen :

1) Durch wiederholte Injektionen von den toten Tuberkelbazillen konnte Verf. die allgemeine Amyloidose bei Kaninchen hervorrufen.

2) Von den Injektionsstellen ist die intraperitoneale am geeignetesten, dann die subkutane, die intravenöse Injektion indessen ungeeignet.

3) Als Lieblingsorgane ist Verf. von der Niere zu nennen; an der Milz ist die Amyloidablagerung relativ minder. 